(Linnean Soc. Fourn. vol. xiv. p. 278) he had given a series of experiments made on ants with light of different colours, in order if possible to determine whether ants had the power of distinguishing colours. For this purpose he utilised the dread which ants, when in their nest, have of light. Not unnaturally, if a nest is uncovered, they think they are being attacked, and hasten to carry their young away to a darker, and, as they suppose, a safer place. He satisfied himself, by hundreds of experiments, that if he exposed to light the greater part of a nest, but left any part of it covered over, the young would certainly be conveyed to the dark portion. In this manner he satisfied himself that the different rays of the spectrum act on them in a different manner from that in which they affect us; for instance, that ants are specially sensitive to the violet rays. But he was anxious to go beyond this, and to attempt to determine how far their limits of vision agree with ours. We all know that if a ray of white light is passed through a prism, it is broken up into a beautiful band of colours-the spectrum. To our eyes it is bounded by red at the one end and violet at the other, the edge being sharply marked at the red end, but less abruptly at the violet. But a ray of light contains besides the rays visible to our eyes others which are called, though not with absolute correctness, heat rays and chemical rays. These, so far from being bounded by the limits of our vision, extend far beyond it, the heat rays at the red, the chemical rays at the violet end. He wished under these circumstances to determine if possible whether the limit of vision in the case of ants was the same as with us. This interesting problem he endeavoured to solve as follows:If an ant's nest be disturbed the ants soon carry their grubs and chrysalises underground again to a place of safety. Sir John, availing himself of this habit, placed some ants with larvæ and pupæ between two plates of glass about one-eighth of an inch apart, a distance which leaves just room enough for the ants to move about freely. He found that if he covered over part of the glass with any opaque substance the young were always carried into the part thus darkened. He then tried placing over the nest different coloured glasses, and found that if he placed side by side a pale yellow glass and one of deep violet the young were always carried under the former, showing that though the light yellow was much more transparent to our eyes, it was, on the contrary, much less so to the ants. So far he had gone in experiments already recorded; but he now wished, as already mentioned, to go further, and test the effect upon them of the ultra-violet rays, which to us are invisible. For this purpose, among other experiments, he used sulphate of quinine and bisulphide of carbon, both of which transmit all the visible rays, and are therefore perfectly colourless and transparent to us, but which completely stop the ultra-violet rays. Over a part of one of his nests he placed flat-sided bottles containing the above-mentioned fluids, and over another part a piece of dark violet glass; in every case the larvæ were carried under the transparent liquids, and not under the violet glass. Again, he threw a spectrum into a similar nest, and found that if the ants had to choose between placing their young in the ultra-violet rays or in the red they preferred the latter. He infers therefore that the ants perceive the ultra-violet rays, which to our eyes are quite invisible.

Now as every ray of homogeneous light which we can perceive at all appears to us as a distinct colour, it seems probable that these ultra-violet rays must make themselves apparent to the ants as a distinct and separate colour (of which we can form no idea), but as unlike the rest as red is from yellow or green from violet. The question also arises whether white light to these insects would differ from our white light in containing this additional colour. At any rate, as few of the colours in nature are pure colours, but almost all arise from the combination of rays of different wave-lengths, and as in such cases the visible resultant would be composed not only of the rays which we see, but of these and the ultraviolet, it would appear that the colours of objects and the general aspect of nature must present to them a very different appearance from what it does to us.

Similar experiments which Sir John also made with some of the lower Crustacea point to the same conclusion, but the account of these he reserved for a future occasion. He then proceeded to describe some experiments made on the sense of direction possessed by ants, but it would not be easy to make these intelligible without figures. After detailing some further experiments on the power of recognising friends, he gave some facts which appear to show that ants by selection of food can produce either a queen or a worker at will from a given egg. Lastly he stated that he had still some ants which he had commenced to observe in 1874 , and which are still living and in perfect health; they now therefore must be more than seven years old, being therefore by far the oldest insects on record.

\section{THE WEATHER AND HEALTH OF LONDON ${ }^{1}$}

$T O$ the statistician London affords materials for the prosecution of many inquiries such as could not be obtained from the statistics of any other city either in ancient or modern times. Among the more important of these inquiries are those which relate to questions suggested by the enormous aggregation of human beings over a limited area which London presents on a scale absolutely unparalleled in the world's history. It is one of these questions we bring before you this evening, viz., the influence of the climate on the health of the people of London.

The relation of weather to health is a question which has engaged the attention of Dr. Arthur Mitchell and myself for many years. In an early stage of the inquiry our attention was mainly directed to Scotland, and more particularly to the data supplied by its eight large towns ; but it was soon found that, owing to the sparseness and other conditions of the population, and to the fact that the division of time into months only, adopted by the Registrar-General for Scotland, they were not sufficiently minute to show the true relations of weather to the fluctuations of the death-rate through the year. In truth it was only after not a little unsuccessful labour, and what could at best be characterised as no more than partially successful work, that we resolved eight years ago to open the discussion of the whole subject by an exhaustive examination of the meteorological and vital statistics of London and London alone. More specifically our reasons for the selection of London were that it afforded data from (I) an enormous population spread over an area so limited that it might be regarded as having one uniform climate during each of the seasons of the year; (2) full weekly reports of weather and the deaths from the different diseases; and (3) returns extending over a sufficiently long period.

In the case of diseases such as diarrhœe and bronchitis, which seem to be directly and immediately under the influence of temperature, and such epidemics as scarlet fever and whooping cough, the rate of mortality from which is largely determined by season and weather, a comparatively small number of years is required to give a satisfactory approximation to their true weekly curve of mortality. But as regards the great majority of diseases, it quickly became apparent that a thirty years' average was required in the construction of curves which could be accepted as true "constants" for the diseases to which they refer. The thirty years beginning with 1845 were therefore adopted. An examination of the curves shows that some of their striking features, particularly those

\footnotetext{
I Substance of a Lecture delivered at the Royal Institution, March 25.
} 
showing the complications of special diseases and their connections with each other, which the weekly averages disclose, would entirely disappear if monthly averages only were employed.

The curves of the more prominent and interesting of the diseases are shown on the accompanying woodcuts, the straight black line in each figure being drawn to represent the mean weekly death-rate on an average of the fifty-two weeks of the year, and the figures on the margin the percentages above or below the average. With this general average the mean death-rate of each week is compared and the difference above or below cal-
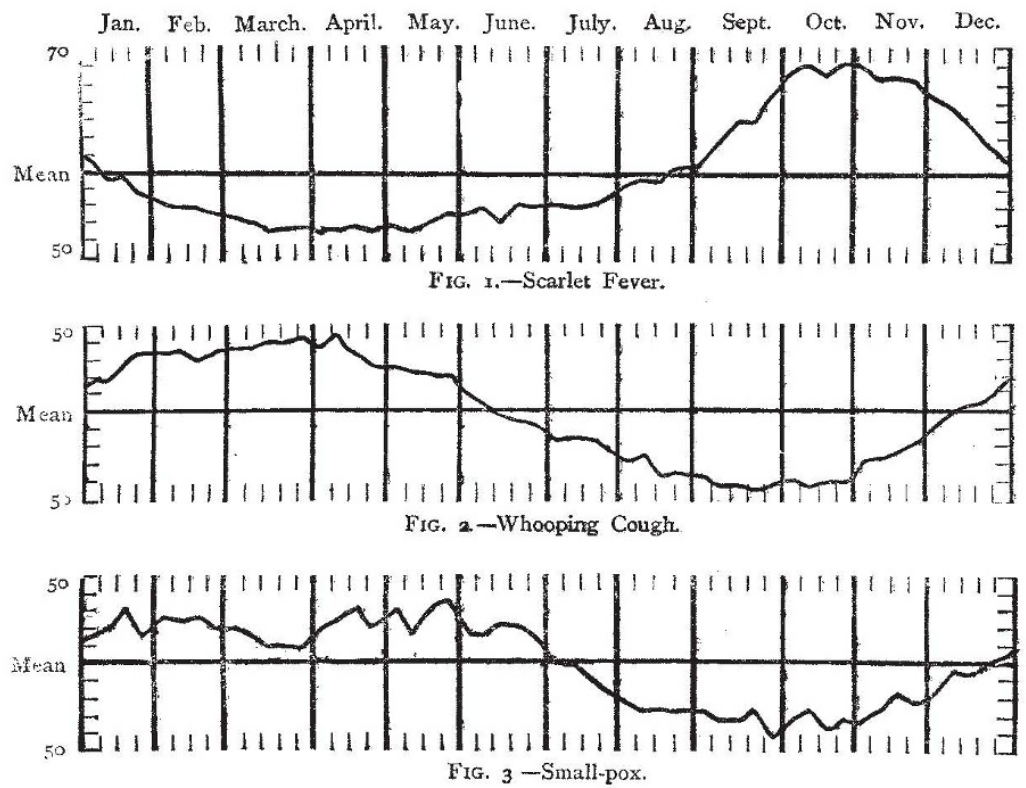

culated in percentages, which, when plus, are placed above the mean line of the figure, and when minus, below it. Thus as regards scarlatina (Fig. I), the mean of the fifty-two weeks is $49^{\circ} 6$; on the first week of January it is 7 per cent. above the mean, from which time it continues to fall to the annual minimum, 35 per cent. below the mean in the middle of March, thence rises to the mean in

the end of August; to the annual maximum, 60 per cent. above the mean, in the end of October, and thereafter steadily falls. The portion of the curve above the mean line thus shows the time of the year when, and the degree to which, the mortality from scarlatina is above its average and the portion below the line when it is under it.

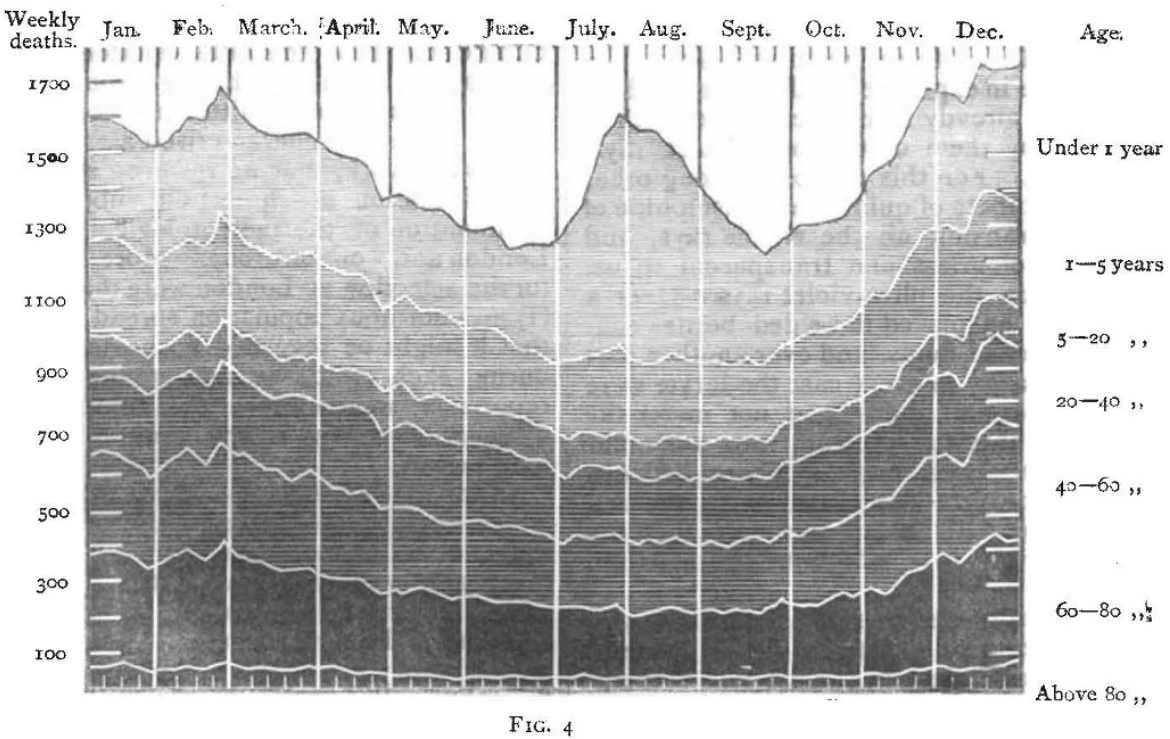

Fig. 2 shows similarly the distribution of the mortality / the minimum period of the other, and vice versâ. It is from whooping-cough through the weeks of the year, and also seen that the mortality curve for small-pox (Fig. 3 ) Fig. 3 the distribution of the mortality from small-pox. It is quite distinct from the other two curves.

is seen at once that the mortality curve from scarlatina is In order to ascertain the degree of steadiness of these precisely the reverse of the curve of whooping-cough, the curves, a curve was calculated and drawn for each of maximum death-rate period of the one corresponding to the seven epidemics of scarlatina and for each of the 
Jan. Feb. March April. May. June. July. Aug. Sept. Oct. Nov. Dec.

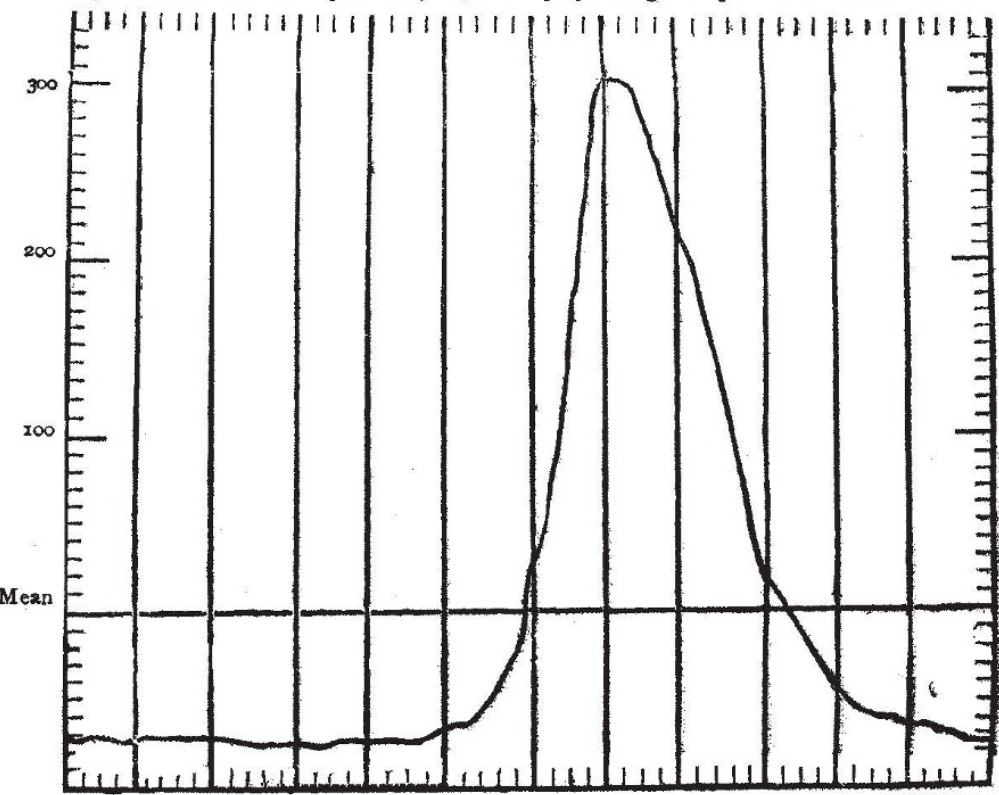

FIG. 5.-Diarrhcea.

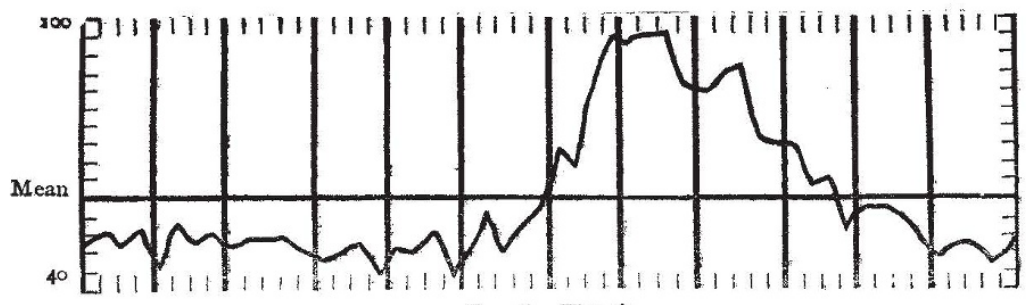

FIG. 6.-Thrush
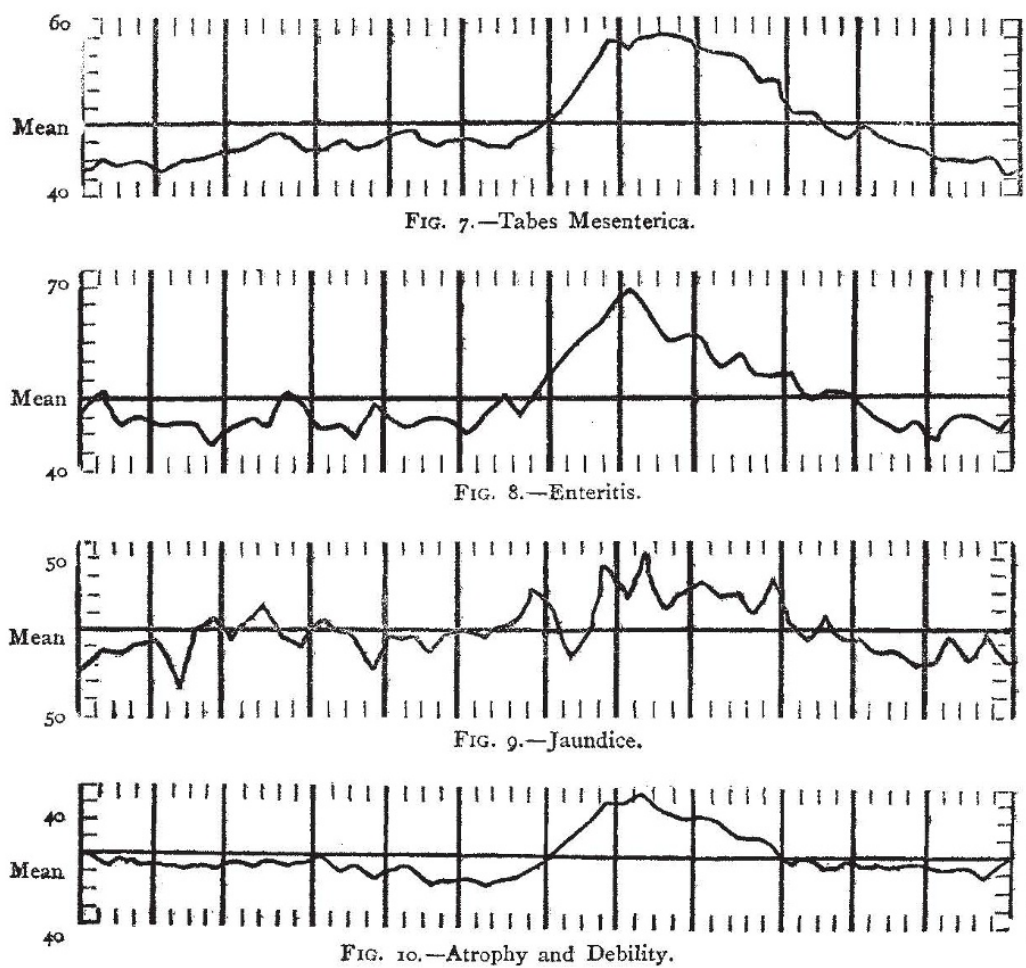

eight epidemics of whooping-cough during the thirty years, with the instructive result that the curve for each of the separate epidemics was substantially identical with the general curve for the whole thirty years' period, each of the four prominent phases of each curve occurring all within a week of each other. As regards the smallpox curve, if the deaths during the epidemic of 1870-72, by far the most fatal of all the epidemics during the thirty years, be deducted from the general result, we obtain a curve which is substantially the same curve as that for the whole thirty years, but only less pronounced. From these results it follows, and the remark is of general application to all the curves, that the mortality curves for the different diseases arrived at in this inquiry may be regarded as true constants of these diseases for London.

The climate of London, looked at as influencing the bealth of the people, may be divided into six types of weather accerding to the season of the year. These are respectively-

Period 1.-Damp and cold, fourth week of October to third week of December.

Period 2.-Cold, fourth week of December to third week of February.

Period 2.-Dry and cold, fourth week of February to second week of April.

Period 4.--Dry and warm, third week of April to third week of June.

Period 5.-Heat, fourth week of June to first week of September.

Period 6.-Damp and warm, second week of September to third week of October.

The outstanding features of the death-rate in its relation to the varying types of weather through the year are shown by the top curve of Fig. 4, which represents the total mortality for all ages. This curve shows two maxima in the course of the year: the one, by far the larger of the two, extending over six months from November to April, and the other embracing the period from about the beginning of July to the autumnal equinox. It will be also observed that the comparatively short-continued but strongly-pronounced summer maximun is restricted to mere infants, whereas the larger winter maximum is a feature of the curves for all ages.

Figs. 5 to Io are representative curves of those diseases which go to form the summer maximum when "heat" is the chief characteristic of the weather. The direct relation of the progress of mortality from diarrhrea to temperature is strikingly seen in the startling suddenness with which the curve shoots up during the hottest months of the year, and the suddenness, equally startling, with which it falls on the approach of colder weather. The curves for dysentery, British 
cholera, and cholera are substantially the same as the curve for diarrhœa, all showing the same close obedience to temperature. It is a noteworthy circumstance that these four curves group themselves into pairs-diarrhcea and British cholera on the one side, and dysentery and Asiatic cholera on the other. The chief points of difference are that dysentery and Asiatic cholera begin markedly to rise considerably later than the other two allied diseases, attain their maximum a month later, and fall more rapidly than they rose, the annual phases being nearly a month later than those of diarrhœea and British cholera.

The peculiarly malignant character of summer diarrhœa among young children under five years of age may be shown by the weekly mortality from diarrhcea, rising from 20 in the middle of June, to 342 in the first week of August, 1880, when the mean temperature of July and August was about the average. In July, 1876, when the temperature was $3^{0.6}$ above the average, the weekly mortality from diarrhœa among children rose to 502 on the last week of that month. On the other hand, during the cold summer of 1860 , the diarrhœa mortality for all ages did not in any week exceed ninety.

Of the British large towns the lowest mortality from summer diarrhoea is that of Aberdeen, which has the lowest summer temperature. The diarrhœa mortality of

Jan. Feb. March. April. May. June. July. Aug. Sept. Oct. Nov. Dec.

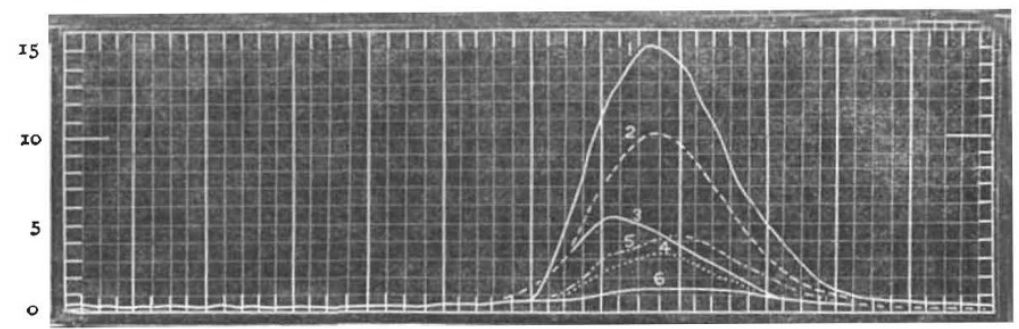

FIG. II.-Weekly Deaths from Diarrhca calculated on the Annual Mort 3 lity per rooo of the population.

each town is found from year to year to rise proportionally with the increase of temperature, but the rate of increase differs greatly in different towns, thus pointing to other causes than mere weather, or the relative temperatures and humidities of these towns, as determining the mortality. Fig. I I shows the weekly death-rate from diarrhœa for six of the large British towns, viz., Leicester, curve I ; Liverpool, 2 ; London, 3; Bristol, 4; Portsmouth, 5; and Edinburgh, 6; from which it is seen that though the summer temperature of London is hotter than that of Liverpool and Leicester, its diarrhœa mortality is very much less. In this respect London contrasts very favourably with the great majority of British large towns, showing its sanitary conditions generally are at least fairly satisfactory; but inasmuch as it is somewhat in excess of a few of the towns whose summer temperature is scarcely lower, London offers problems in this field to the sanitary reformer for his solution.

Figs. 6 to ro give the curves for thrush, tabes mesenterica, enteritis, jaundice, and atrophy and debility, all of which have their maximum fatality during the hottest period of the year, and all of which, it will be noted, are bowel complaints. Indeed with the apparent exception of one or two nervous diseases, all those diseases which indicate an increase in their death-rate during the summer months are bowel complaints. ALEXANDER BUCHAN

\section{(To be continued.)}

\section{NOTES}

THE British Association having decided to hold its annual meeting this year at York, where, fifty years ago, its first meeting was held, it has been thought that advantage should be taken of this jubilee meeting to show, as far as possible, the progress which has been made during the past half century in the construction of instruments of scientific research, and, with this view, it has been decided to invite men of science, scientific societies, and manufacturers to exhibit, at the meeting, instruments of the latest patterns, and tools used in their construction; and if the science be fifty years old, the instruments used in 1831 ; otherwise specimens of the earliest patterns that can be found. The Exhibition will $b$; for the week of the meeting only, viz. from August $3 \mathbf{I}$ to September 8. To ensure that specimens intrusted for exhibition shall be as advantageously placed as possible, a special sub-committee, called "The Museum SubCommittee," has been formed at York, who will be happy to afford every possible information. The sub-committee includes several gentlemen who have had considerable experience in the arrangement of exhibitions, and they will give their personal attention to the unpacking, arrangement, and care of objects intrusted to them, so that the risk of injury will be reduced to a minimum. The articles exhibited will be insured against fire, and provision will be made for police protection; beyond this the committee does not hold itself responsible. It is requested that exhibitors will put a value on their exhibits, in order that the necessary insurance may be made. The proposed Exhibition will also include apparatus and specimens illustrative of papers to be read at the Association meeting, which the authors may be willing to allow to be examined at leisure, as well as instruments constructed for the prosecution of special researches which have not yet become articles of ordinary commerce. It is very desirable that such instruments and apparatus should be exhibited in action, if arrangements can be made for the purpose.

THE thirtieth meeting of the American Association for the Advancement of Science will be held at Cincinnati, Ohio, commencing on Wednesday, August 17, and following days. As it is generally believed that the Cincinnati meeting will be the largest and most important scientific meeting ever held in the West, every effort will be made by the Local Committee to prepare, in advance of the meeting, a satisfactory general programme for the week. At the Boston meeting several changes in the constitution were proposed, which will come up for action at Cincinnati, the object of the changes being the reorganisation of the sections, and also to extend the scope; of the Association. Should these changes be adopted, the Association will embrace eight sections of equal standing, each presided over by a vicepresident, and having its own secretary and sectional committee. The following is the division proposed, and upon which final action will be taken at Cincinnati:-Sec. A. Physics; Sec. B. Astronomy and Pure Mathematics; Sec. C. Chemistry, including its applications to Agriculture and the Arts; Sec. D. Mechani- 